\title{
Inductanceless high order low frequency filters for medical applications
}

\author{
Noor Thamer Almalah, Faris Hasan Aldabbagh \\ Department of Electrical, Engineering College, University of Mosul, Mosul, Iraq
}

\begin{tabular}{l}
\hline \hline Article Info \\
\hline Article history: \\
Received Mar 31, 2021 \\
Revised Sep 8, 2021 \\
Accepted Oct 6, 2021 \\
\hline
\end{tabular}

Keywords:

Embeded IC filter

Frequency dependent negative resistance

Inductancess filter

Lowpass filter

\begin{abstract}
In this paper, a designed circuit used for low-frequency filters is implemented and realized the filter is based on frequency-dependent negative resistance (FDNR) as an inductor simulator to substitute the traditional inductance, which is heavy and high cost due to the coil material manufacturing and size area. The simulator is based on an active operation amplifier or operation transconductance amplifier (OTA) that is easy to build in an integrated circuit with a minimum number of components. The third and higher-order Butterworth filter is simulated at low frequency for low pass filter to use in medical instruments and low-frequency applications. The designed circuit is compared with the traditional proportional integral controller enhanced (PIE) and $\mathrm{T}$ section ordinary filter. The results with magnitude and phase response were compared and an acceptable result is obtained. The filter can be used for general applications such as medical and other low-frequency filters needed.
\end{abstract}

This is an open access article under the CC BY-SA license.

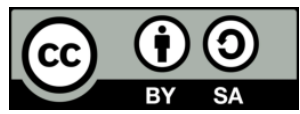

\section{Corresponding Author:}

Faris Hasan Aldabbagh

Department of Electrical, Engineering College, University of Mosul

Al Majmoaa Street, 41002 Mosul, Iraq

Email: f.h.aldabbagh@uomosul.edu.iq

\section{INTRODUCTION}

The filter analysis is very important in systems for signal processing [1]. Filters are used to accept, adjust and reject all desirable, undesirable frequencies of the signal respectively, generally filters classification into active or passive with four bands of frequencies high-pass, band-pass, band-stop, and low-pass. Though the most informational filter in the literature review are Butterworth, Chebyshev and Bessel filters [2]. A low-power medical amplifiers which can be integrated into a single chip, capable of processing signals in very low frequencies [3]-[8]. The main problem of the low pass passive filter, usually, is the size and cost of the inductors, where the passive components (inductance, capacitive) is not suitable to design in a low pass filter for medical applications, additionally, the drawback of the passive inductor is a requirement of excessive chip area. In addition, passive inductors are vulnerable to process fluctuations and suffer from resistive losses [9]-[12].

This paper illustrates some of the ways to build filters without inductors. The proposed technique exploits the generalized inductance converter (GIC). There is a need to develop low-power biological amplifiers, which can be integrated into a single chip, capable of processing signals in very low frequencies [13]-[15]. The present work of paper aims to build a low-pass filter, of order N, operate in very low frequency. This filter has a wide range of applications in biological signals with very low-frequency characteristics, for example, the electrocardiogram (ECG) and other medicals signals.

A few years ago, analog filters have been attracted large attention. Current conveyors have become very popular as these devices provide high performance and greater functional versatility in realizations 
[16], [17]. In [9] proposes a new grounded/floating frequency-dependent negative conductance (FDNC) simulator, and a non-ideal frequency-dependent negative resistance (FDNR) simulator, based on deployment of voltage differencing transconductance amplifiers (VDTA), along with two grounded capacitances. In [10] three new circuit configurations for realizing lossless and lossy grounded inductance simulators are proposed. Also, two topologies for realizing grounded FDNR and grounded capacitance simulators are developed.

The researcher in [11] presented a circuit configuration that can act like a grounded impedance simulator/grounded impedance scaling circuit it can simulate electronically tunable grounded resistance/capacitance/inductance/FDNR and also work as a grounded impedance multiplier circuit, which can scale up/scale-down the value of arbitrary grounded impedance with an electronically controllable multiplication factor. In [12] described a grounded lossy inductance (grounded parallel RL network) simulator configuration employing two Current differencing differential input transconductance amplifiers (CDDITAs), one resistance (grounded), and one capacitance (grounded) is completely free from active/passive component matching conditions and its behavior is studied considering non-ideal current-voltage transfer ratios. To validate the usefulness of the presented parallel resistor inductance (RL) simulator some filter designs are developed. In this work, low frequency, low pass $\mathrm{N}$ order filters were realized using the frequency-dependent negative resistance FDNR technique to substitute the traditional inductance. The filter magnitude and phase against frequency responses are introduced.

\section{RESEARCH METHOD}

\subsection{Proposed filter design circuit}

The filter sample proposed filter configuration of the implemented low-pass filter (LPF) is illustrated and shown in Figure 1. As it can be seen, the analog filter for low frequency using an inductor to reject the undesired frequency and noise in the useful signal. These inductors it's difficult to build and fabricate in the integrated circuit. The recent idea is to replace the inductors with a new simulated circuit by using an active operation amplifier as a transconductance convertor GIC. One of these implementations is called a frequency-dependent negative resistor FDNR.

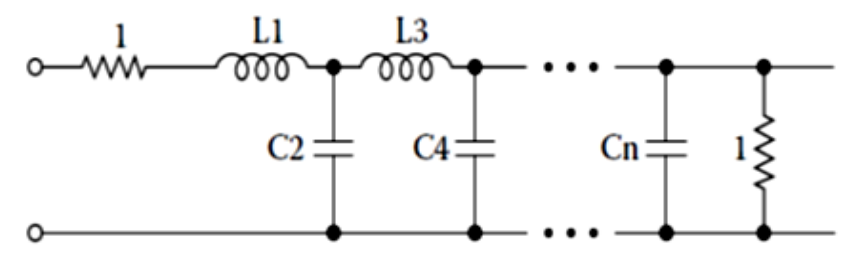

Figure 1. T section Butterworth low pass $\mathrm{N}^{\text {th }}$ filter

This work offered a third and fifth-order LPF Butterworth filter type that the response of a filter is maximally flat, the approximation is defined by:

$$
f(\omega)=\omega^{N}
$$

where $\mathrm{N}$ is the degree of the filter prototype network and to determine the element value of the $\mathrm{N}$ the order [18].

$$
\begin{aligned}
& g_{n}=2 \sin \left[\frac{(2 n-1) \pi}{2 N}\right] \\
& g_{n}=L_{n} \text { or } C_{n}(n=1,2,3 \ldots \ldots N-1)
\end{aligned}
$$

This approximation for $w c=1$ rad $\backslash s e c$. The FDNR elements are equivalent to inductors in behavior and impedances which can be used to substitute the inductor element and eliminate the large size, heavy, and cost of traditional filter in middle and low frequency.

\subsection{Design procedure}

The passive filter in Figure 1 is to be replaced by an active low pass filter using the FDNR technique for general applications such as medical and others. For the 3rd order as a design circuit, the inductors are 
eliminated and the circuit converted to an inductor simulated noted as D element the equivalent circuit is shown in Figure 2. The resistance and inductance were transferred to capacitance and resistance respectively and the capacitance was transferred to the D element, the last can be implemented as an operational amplifier configuration Figure 3.



Figure 2. Show the GIC approximation

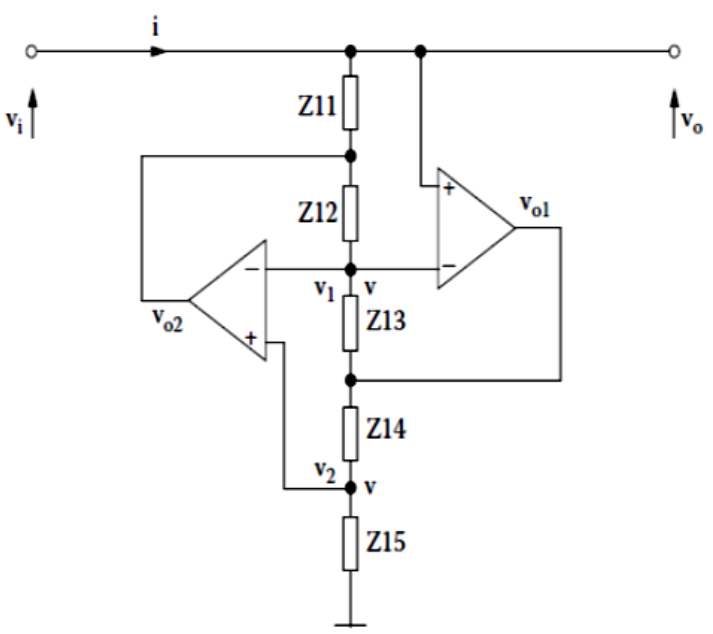

Figure 3. The op amp operation FDNR element

The total D FDNR element impedance according to [19]-[23] is equal to,

$$
Z=\frac{V}{I}=\frac{Y_{12} Y_{14}}{Y_{11} Y_{13} Y_{15}}=\frac{Z_{11} Z_{13} Z_{15}}{Z_{12} Z_{14}}
$$

To calculate the D FDNR elements impedances they use the following equations,

$$
Z=\frac{V}{I}=\frac{C_{11} R_{13} C_{15}}{R_{12} R_{14}}
$$

In the S domain, the impedance became

$$
Z=\frac{R_{13}}{S^{2} R_{13} R_{14} C_{11} C_{15}}=\frac{1}{w^{2} D}
$$

where $S=j w$

$$
D=\frac{R_{13} R_{14} C_{11} C_{15}}{R_{13}}
$$

Assuming Z12, Z13, and Z14 are resistances where Z11, Z15 are capacitances and substitute in (4). Replacing the impedances of the FDNR of D element as in circuit Figure 4, which is easy to implement using 
traditional operation amplifier and simple components which can be built easily in integrated circuits. In the second filter realization as shown in Figure 5, the $1 \mathrm{rad} / \mathrm{sec}$ cut-off frequency five order Butterworth low pass filter with origin inductors. And modified to D element simulated FDNR and the circuit become as shown in, Figure 6 with the same characteristics of the original and designed filter. Figure 6 shows the fifth-order converted filter, with a cutoff frequency: i) $\mathrm{Cnew}=0.1 \mu \mathrm{f}$, ii) Impedance scaling factor (ISF) $=\mathrm{Cnor} / \mathrm{cnew}$ $=159.15 \mathrm{k} \Omega$, iii) Frequency scaling factor $(\mathrm{FSF})=$ wnew $/$ wnor $=200 \pi$, iv) Rnew $=$ Rnor $*$ ISF, and v) $\mathrm{D}$ is equal to $\mathrm{D}=\mathrm{Cnor} / \mathrm{ISF} * \mathrm{FSF}$.

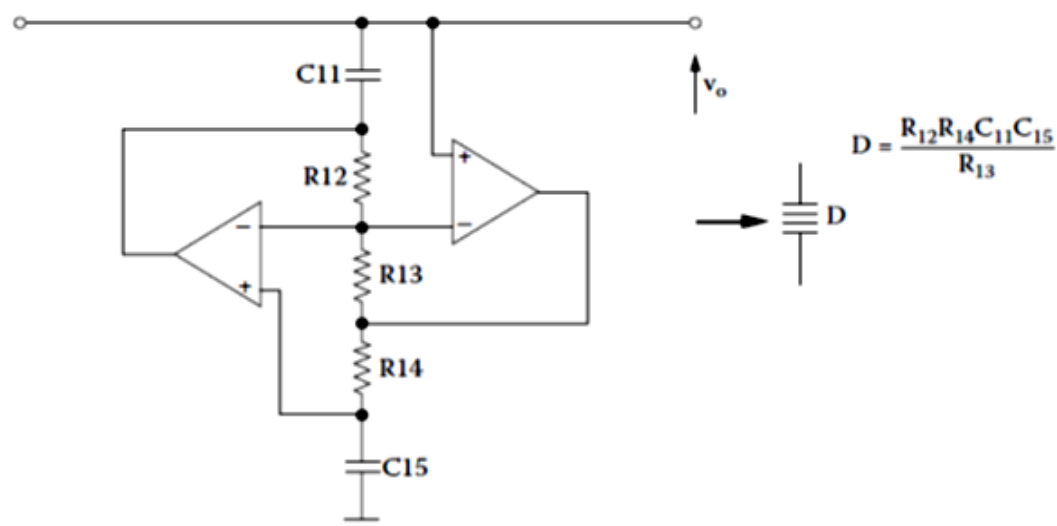

Figure 4. The D element reconstructed circuit of D FDNR

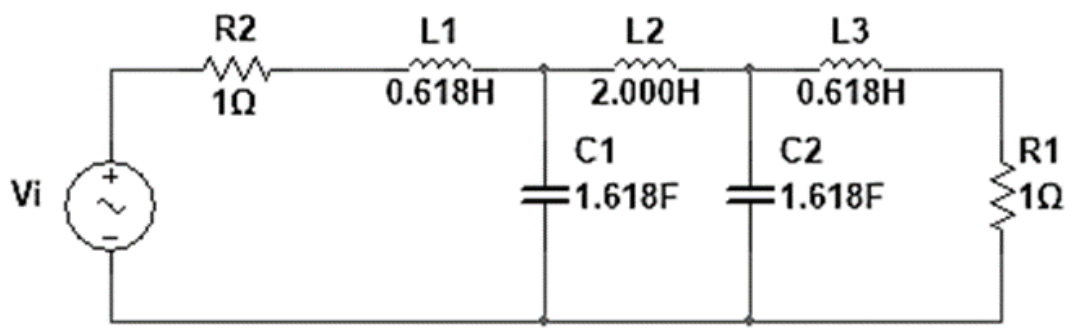

Figure 5. The origin low pass filter

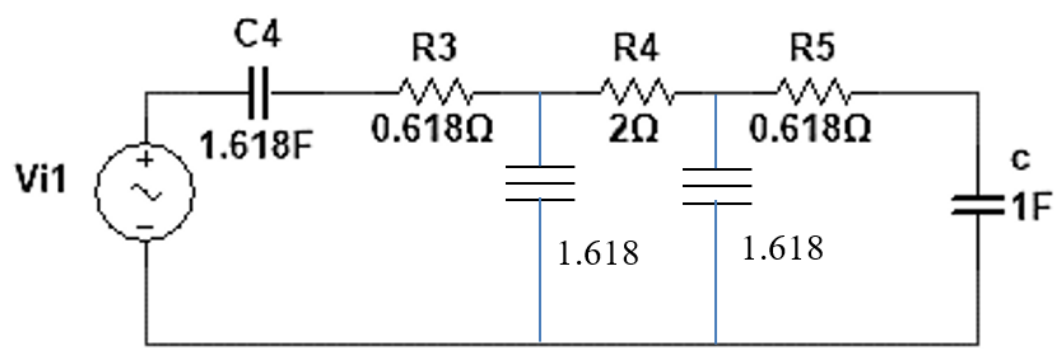

Figure 6. The converted filter

\section{RESULTS AND DISCUSSION}

\section{1. $3^{\text {rd }}$ order LPF with FDNR}

3rd order LPF with FDNR inductance replaced circuit under tests, results of magnitude and phase frequency response shown in Figure 7(a) and (b) respectively, using PSPICE software light free package. The results show, the $-3 \mathrm{~dB}$ cutoff frequency of the magnitude and phase is about $100 \mathrm{~Hz}$ as theoretically designed, which is frequency difficult to realized using traditional real coil inductance. 


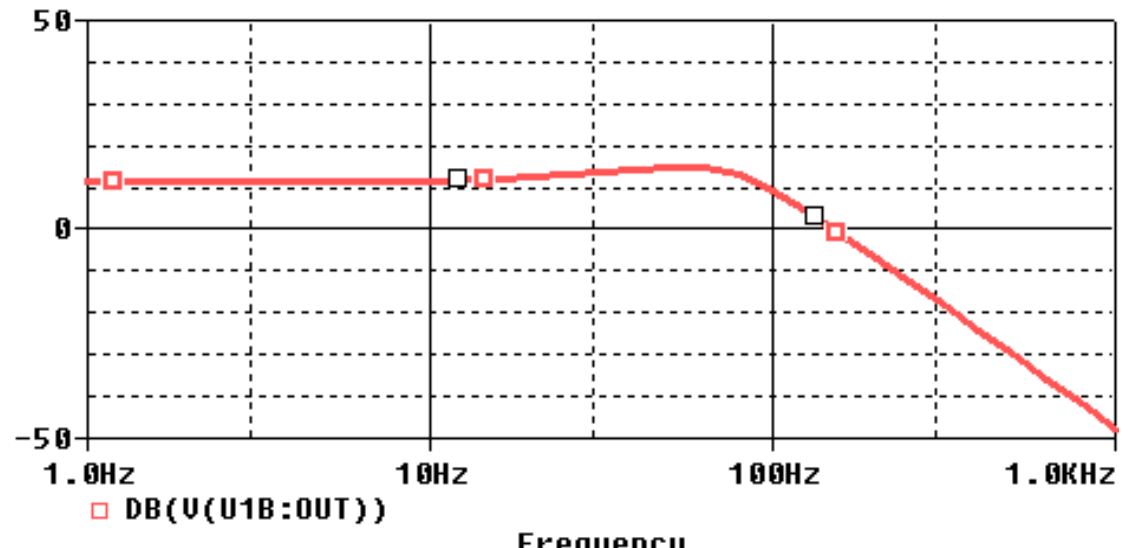

Frequency

(a)

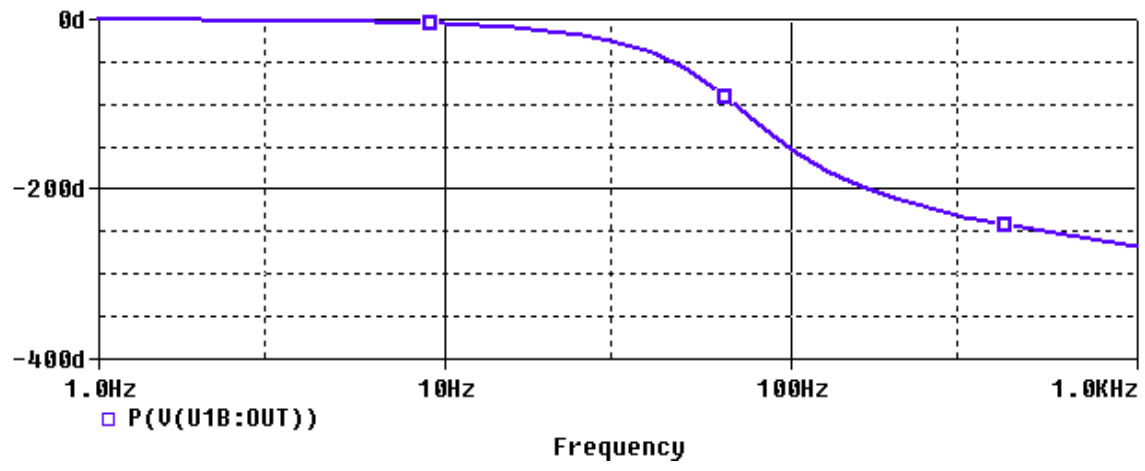

(b)

Figure 7. Third order frequency response of the filter versus (a) magnitude output gain in $\mathrm{dB}$ and (b) phase in degree

\section{2. $5^{\text {th }}$ order LPF with FDNR inductance}

$5^{\text {th }}$ order LPF with FDNR inductance replaced circuit under tests, results of magnitude and phase frequency response shown in Figures 8(a) and (b) respectively. The fifth-order low pass filter circuit diagram PSPICE drawing is shown in Figure 9, the filter responses tests from the three stages, the first, second, and third FDNR outputs of the circuit. The filter frequency response of the designed filter can be improved change the output resistance value of the circuit as shown in Figure 10, which means the filter can be realized as close to ideal without loading effect as possible.

\subsection{Total harmonic distortion (THD)}

The important figure of Merit used to test the quality of the output signals is the level of harmonics in voltage or current waveform [24]. Total harmonic distortion (THD) standards and can be highly objectionable for voltage harmonic sensitive loads. THD is a ratio of the RMS value of the harmonics to the fundamental of the voltages or currents, the distortion percent of the component with the fundamental frequency indicates the signal distortion according to the relations [25].

$$
T H D=\sqrt{\frac{\text { sum of the squares of all harmonics voltage }}{\text { fundamental voltage square }}} * 100 \%
$$

In the $3^{\text {rd }}$ designed filter, the THD was calculated to determine the added noise and comparing with the original sinusoidal signal. Figure 11 shows the filter fundamental at the original component and harmonics components. The signal spectrum indicates the operation and quality of the filers. The same spectrum analysis was done on $3^{\text {rd }}$ order filter using the FDNR technique proposed as shown in Figure 12, the figure shows the large fundamental signal compared to the second harmonics signal, which indicated the good operation of the filter. Also, the same analysis was done to the 5th order without and with the FDNR 
filter. In Figure 13, the first and second harmonics shown, where in the Figure 14 spectrum of the filter using FDNR configuration.

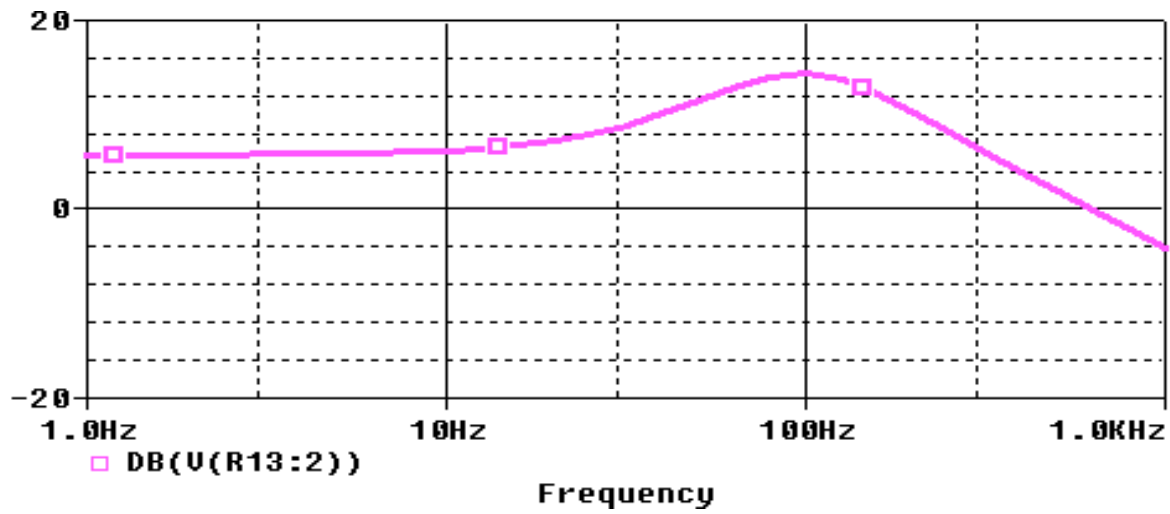

(a)

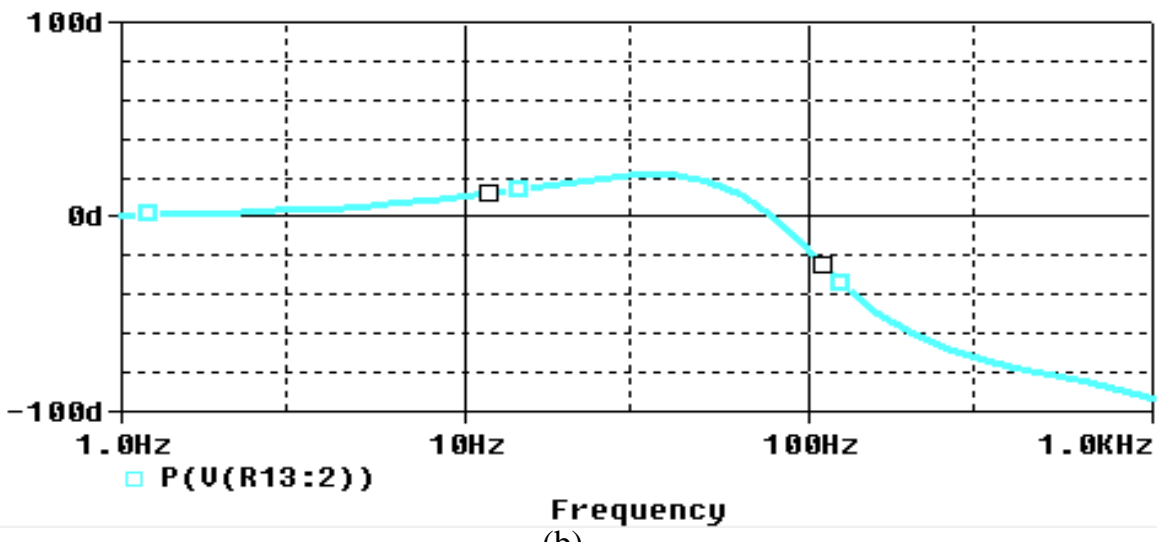

(b)

Figure 8. Fifth order frequency response of the filter versus, (a) magnitude in $\mathrm{dB}$ and (b) phase in degree



Figure 9. The fifth order PSPICE low pass filter with the probs of measured signals circuit diagram 


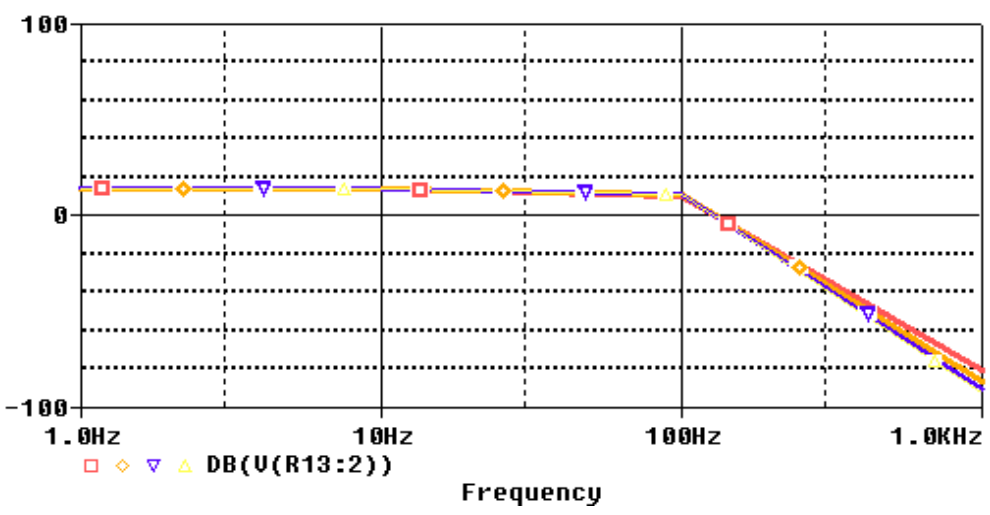

Figure 10. The output resistance effect on the response of the filter

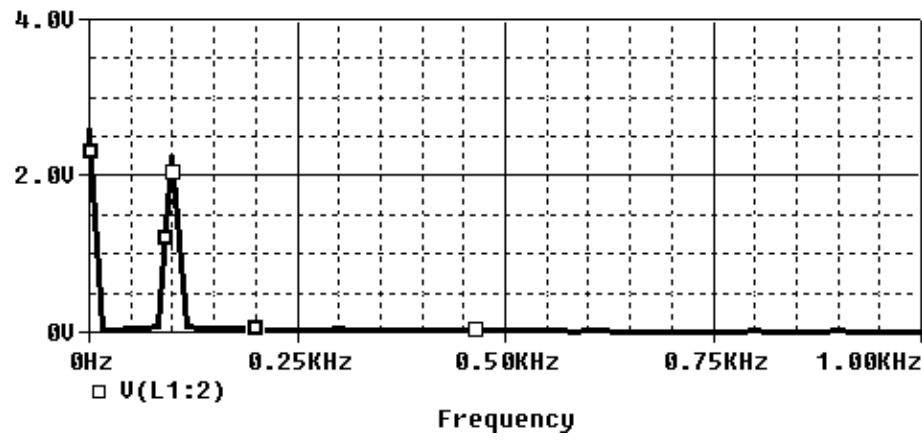

Figure 11. The FFT of the origin 3order filter

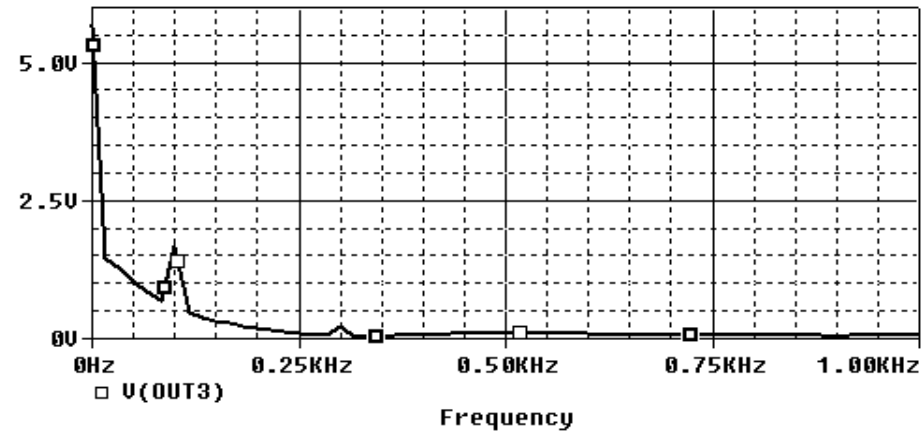

Figure 12. The FFT of 3 order FDNR used filter

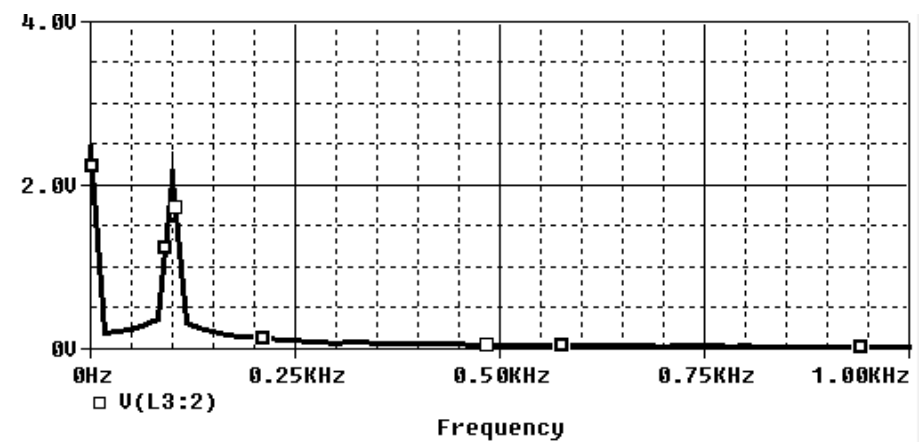

Figure 13. The FFT of 5 order orign filter 


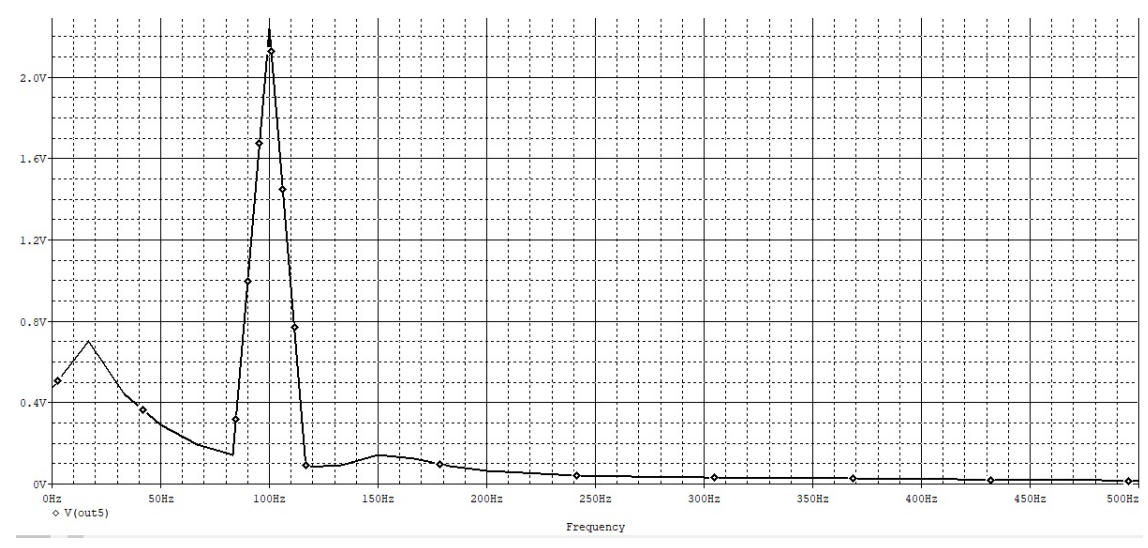

Figure 14. The FFT of 5 order FDNR filter

As a result of the total harmonics distortion THD, of the two filters used later can be summarized in Table 1, the obtained measured shows that percent of the $3^{\text {rd }}$ order has a significant improvement by using FDNR active filter. Where the 5 order filter an improvement less obtained than 3 order but also acceptable results. The THD of the ordinary filters and FDNR filters is the better than original filters using inductors.

Table 1. The THD different in the two filters without and with FDNR filters

\begin{tabular}{ccc}
\hline Order & Origin & FDNR \\
\hline $3 \mathrm{TH}$ & 2.622 & 8.33 \\
$5 \mathrm{TH}$ & 3.98 & 2.73 \\
\hline
\end{tabular}

\section{CONCLUSION}

This paper proposed and designed two low pass filters as the field of this research. The two designed filters using FDNR instead of heavy inductors. The third and fifth order low pass filter was realized and simulated for magnitude and phase frequency response. The results obtained are very close to the inductors filters compared to the FDNR's filters which indicates the advantages of using these types of modified design to use in integrated circuits in medical or low-frequency applications. Additionally, the quality of the output signals is tested and measured in total harmonic distortion THD and based on the results show that the fifth order is better than the third-order in THD percent of harmonics quality.

\section{REFERENCES}

[1] E. E. Tsakonas, N. D. Sidiropoulos, and A. Swami, "Time-frequency analysis using particle filtering: Closed-form optimal importance function and sampling procedure for a single time-varying harmonic," in 2006 IEEE Nonlinear Statistical Signal Processing Workshop, Sep. 2006, pp. 9-12, doi: 10.1109/NSSPW.2006.4378808.

[2] K. Karki, "Active low-pass filter design," Application Report LOAO49A, 2000.

[3] L. Syed, S. H. Hasan, H. Rashid, and W. Gulistan, "Designing band pass filter for HF radio's front end," in 2019 International Conference on Communication Technologies (ComTech), Mar. 2019, pp. 60-64, doi: 10.1109/COMTECH.2019.8737794.

[4] W. M. Laghari, M. U. Baloch, M. A. Mengal, and S. J. Shah, "Performance analysis of analog Butterworth low pass filter as compared to Chebyshev Type-I filter, Chebyshev Type-II filter and elliptical filter," Circuits and Systems, vol. 5, no. 9, pp. 209216, 2014, doi: 10.4236/cs.2014.59023.

[5] A. Fernandez-Vazquez and G. Jovanovic-Dolecek, "A new method for the design of IIR filters with flat magnitude response," IEEE Transactions on Circuits and Systems I: Regular Papers, vol. 53, no. 8, pp. 1761-1771, Aug. 2006, doi: 10.1109/TCSI.2006.877891.

[6] S.M. Abdelsayed; M. Jamal Deen; N.K. Nikolova, "A fully integrated low-power CMOS power amplifier for biomedical applications," The European Conference on Wireless Technology, 2005.

[7] S. K. Jagtap and M.D. Uplane, “A real time approach: ECG noise reduction in Chebyshev Type II digital filter," International Journal of Computer Applications, vol. 49, no. 9, pp. 52-53, Jul. 2012, doi: 10.5120/7659-0763.

[8] R. R. Harrison and C. Charles, "A low-power low-noise cmos for amplifier neural recording applications," IEEE Journal of SolidState Circuits, vol. 38, no. 6, pp. 958-965, Jun. 2003, doi: 10.1109/JSSC.2003.811979.

[9] P. B. Petrović, "New floating/grounded FDNC and non-ideal grounded FDNR simulators based on VDTA," Analog Integrated Circuits and Signal Processing, Mar. 2021, doi: 10.1007/s10470-021-01818-x.

[10] M. Faseehuddin, J. Sampe, and S. Hamid Md Ali, "Grounded impedance simulator topologies employing minimum passive elements," International Journal of Engineering and Technology, vol. 7, no. 2.28, May 2018, doi: 10.14419/ijet.v7i2.28.12871.

[11] P. Gupta, M. Srivastava, D. Prasad, A. Roy, and M. K. Verma, "A generalized grounded impedance simulator/grounded impedance scaling circuit with electronic tuning," in 2018 5th International Conference on Signal Processing and Integrated Networks (SPIN), Feb. 2018, pp. 771-776, doi: 10.1109/SPIN.2018.8474111. 
[12] K. Bhardwaj, M. Srivastava, K. Panwar, D. Prasad, and A. Roy, "Grounded series R-L impedance simulator using CDDITA," in 2019 International Conference on Signal Processing and Communication (ICSC), Mar. 2019, pp. 254-257, doi: 10.1109/ICSC45622.2019.8938336.

[13] W. Germanovix, "Micropower low-pass filter for medical electronics devices application," Latest Advances in Information Science, Circuits and Systems, 2012.

[14] C. D. Salthouse and R. Sarpeshkar, "A practical micropower programmable bandpass filter for use in bionic ears," IEEE Journal of Solid-State Circuits, vol. 38, no. 1, pp. 63-70, Jan. 2003, doi: 10.1109/JSSC.2002.806286.

[15] R. Sarpeshkar, R. F. Lyon, and C. Mead, “A low-power wide-dynamic-range analog VLSI Cochlea," Analog Integrated Circuits and Signal Processing, vol. 16, pp. 245-274, 1998.

[16] P. V. A. Mohan, "Practical design and applications of current-mode systems," in Current-Mode VLSI Analog Filters, Boston, MA: Birkhäuser Boston, 2003, pp. 245-423.

[17] E. Sánchez-Sinencio and A. G. Andreou, "Low-voltage/low-power integrated circuits and systems: low-voltage mixed-signal circuits," Choice Reviews Online, vol. 37, no. 01, pp. 37-0349-37-0349, Sep. 1999, doi: 10.5860/CHOICE.37-0349.

[18] I. Hunter, Theory and design of microwave filters. The Institution of Engineering and Technology, Michael Faraday House, Six Hills Way, Stevenage SG1 2AY, UK: IET, 2001.

[19] C.-L. Hsu, M.-H. Ho, Y.-K. Wu, and T.-H. Chen, "Design of low-frequency low-pass filters for biomedical applications," in APCCAS 2006-2006 IEEE Asia Pacific Conference on Circuits and Systems, Dec. 2006, pp. 690-695, doi: 10.1109/APCCAS.2006.342101.

[20] F. Aldabbagh and N. ALMalah, "Low frequency filters design based on frequency dependent negative resistance (FDNR)," in 2018 International Conference on Advanced Science and Engineering (ICOASE), Oct. 2018, pp. 503-506, doi: 10.1109/ICOASE.2018.8548907.

[21] G. H. Rao and S. Rekha, "Time constant enhancement technique for low-frequency filters," Circuits, Systems, and Signal Processing, vol. 39, no. 3, pp. 1213-1226, Mar. 2020, doi: 10.1007/s00034-019-01221-y.

[22] M. M. M. Shobaki, N. A. Malik, A. N. Nordin, and S. Khan, "Acquisition of a very low voltage and a low frequency biomedical signal-frequency selective filter design," in 2014 International Conference on Computer and Communication Engineering, Sep. 2014, pp. 20-23, doi: 10.1109/ICCCE.2014.19.

[23] P. Lawhale and G. Somulu, "Cmos based low pass filter for biomedical applications," in International Conference On Industrial Automation And Computing, 2014, pp. 25-30.

[24] I. V Blagouchine and E. Moreau, "Analytic method for the computation of the total harmonic distortion by the cauchy method of residues," IEEE Transactions on Communications, vol. 59, no. 9, pp. 2478-2491, Sep. 2011, doi: 10.1109/TCOMM.2011.061511.100749.

[25] D. A. Gonzalez and J. C. McCall, "Design of filters to reduce harmonic distortion in industrial power systems," IEEE Transactions on Industry Applications, vol. IA-23, no. 3, pp. 504-511, May 1987, doi: 10.1109/TIA.1987.4504938.

\section{BIOGRAPHIES OF AUTHORS}

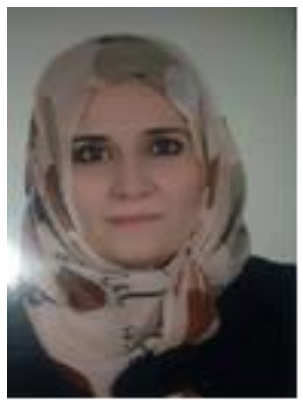

Noor Thamer Almalah (D) SC SC received the B.Sc. degree in Electronic and communication from the University of Mosul, Mosul, Iraq, in 2009 and received M.Sc. degree in 2012 in computer network and commincation from University of Mosul, Mosul, Iraq. His research interests include microelectronics, computer network, commincation, and SoC. She can be contacted at email: Noor.almalah@uomosul.edu.iq.

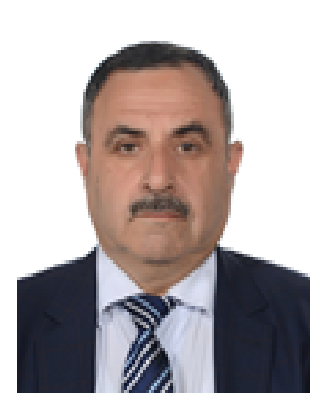

Faris Hassan Aldabbagh (iD $\mathrm{SI}$ SC $\mathrm{P}$ received the MSc degree in Electronic and communication from the University of Mosul, Mosul, Iraq, in 1995 and received Ph.D. degree in 2013 in Solid State Electronics from University of Mosul, Mosul, Iraq. His research interests include microelectronics, solid state electronics, and nanoelectronics. He can be contacted at email: f.h.aldabbagh@uomosul.edu.iq. 